\title{
Perforation of the Nasal Septum and Nasal Ulcers
}

\author{
Maria Pilar Martín-Fortea ${ }^{1}$, Isabel Sanjoaquín-Conde ${ }^{2}$, Santiago Letona-Carbajo ${ }^{2}$, \\ Maria José Crusells-Canales ${ }^{2}$, Julián Cuesta-Muñoz ${ }^{2}$, Juan Antonio Amiguet-García ${ }^{2}$
}

\begin{abstract}
${ }^{1}$ Department of Internal Medicine, Hospital Clínico Universitario “Lozano Blesa”, Zaragoza, Spain; ${ }^{2}$ Department of Infectious Diseases, Hospital Clínico Universitario “Lozano Blesa”, Zaragoza, Spain.

Email: pilarmartinfortea@gmail.com, isanjoaquin@ono.com, santiagoletona@yahoo.es, pcrusells@gmail.com, julcuesta@yahoo.es, amiguet@yahoo.es
\end{abstract}

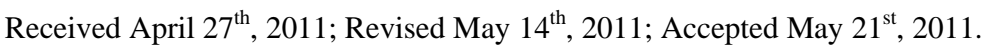

\begin{abstract}
A case about a HIV woman with nasal ulcers is described in this paper. In every inmunodepressed patient who has mucosal or cutaneous ulcers, infection by leishmanial parasites needs to be ruled out, especially when ulcers have not regression with usual treatments. The Leishmanial nasal disease usually shows swelling and mucosal ulcers, that may progress to necrosis. Delaying in appropriate therapy might cause irreversible damage.
\end{abstract}

Keywords: Mucocutaneous Leishmaniasis, Leishmania/HIV Co-Infection, Nasal Ulcer

\section{Introduction}

This is a case about a 36-years-old Paraguayan woman, resident in Spain from 2004. She occasionally consumed cocaine during 2007. In 2008 she was diagnosed as HIV A2 infection (225 CD4/ $\mathrm{mm}^{3}$ [18\%], Viral Load: $8.82 \times$ 105 copies $/ \mathrm{mm}^{3}$ ). She was treated with Nevirapine and Emtricitabine/Tenofovir and presented a good response to treatment. Six months later, she reported rhinorrhea and nasal congestion and she was treated with Levofloxacin $(500 \mathrm{mg} /$ day) and Ibuprofen $600 \mathrm{mg} / 8 \mathrm{~h}$ empirically. After 2 weeks nasal septum perforation was proven. Initially that perforation was related to the previous history of cocaine addiction. The patient was treated with Cefuroxime $500 \mathrm{mg} / 12 \mathrm{~h}$ and topical Mometasone every $12 \mathrm{~h}$. However, the symptoms got worse, with vesicles, oedema and redness of nasal skin. After the collection of nasal samples for cultures (fungus, bacterium and mycobacterium) and investigation for Herpes for PCR, the treatment was then changed to Famciclovir $250 \mathrm{mg} / 8 \mathrm{~h}$, but vesicles and oedema showed progression with nose and upper lip deformity, increase of nasal septum perforation and ulcerations of nasal mucosa (Figure 1). Cultures of nasal samples and PCR for herpes were negative. New samples were taken for cultures. Intravenous therapy commenced with Acyclovir $500 \mathrm{mg} / 8 \mathrm{~h}$, Fluconazole $400 \mathrm{mg} /$ day, Imipenem $1 \mathrm{gr} / 8 \mathrm{~h}$ and Amikacin $1 \mathrm{~g} /$ day. The autoimmunity study was negative. Facial CT ruled out the existence of a tumour. A biopsy of nasal-lip skin showed abundant granulomatosis, with epithelioid cells.
Serological tests to Trypanosoma cruzi and Herpes 1-2 were negative, but were positive to Leishmania by using ELISA IgG 2 (positive over 1.1). Serological tests, histology and skin lesion appearance, led to the consideration of a diagnosis of Mucosal Leishmaniasis. New skin samples were collected in order to be sent to Reference

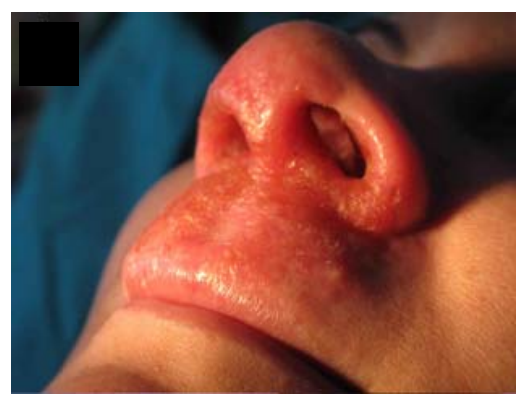

(a)

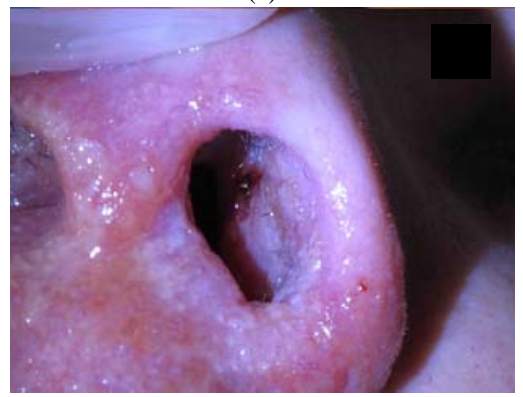

(b)

Figure 1. View of nasal septum perforation (a) and ulcerations of nasal mucosa (b). 
Centre for PCR study and specific Leishmania culture. Pending the outcome of specific cultures, empirical therapy was replaced with liposomal amphotericin B 3 $\mathrm{mg} / \mathrm{kg} /$ day (six weekly doses with a received dose of 900 $\mathrm{mg}$ ). During the second week of treatment, the oedema decreased and the ulcerations started to heal (Figure 2). After treatment, the nose and upper lip skin healed, and nasal mucosa was recovered but the nasal septum perforation remained. Secondary prophylaxis was not proposed due to cellular immunity preservation. After an excellent response to treatment, negative results of PCR and specific culture were received, so that could not identify the etiological specie.

\section{Discussion}

Cutaneous-mucosal leishmaniasis is endemic in Latin America, mainly in Brazil [1], and in most cases it is due to L. braziliensis [2,3]. Around 5\% - 7\% of affected patients present mucosal leishmaniasis [4]. Both clinical presentations may be simultaneous, but the mucosal presentation may appear months or years after healing of the cutaneous presentation [1,4]. Cases of mucosal leishmaniasis have been reported in the Mediterranean basin, but this is uncommon [5,6]. This disease will be found most frequently in the HIV immigration population [7].

The clinical diagnosis of mucosal leishmaniasis was based on lesion appearance and epidemiological analysis [8]. Differential diagnosis arises with other infectious diseases (mycobacterium, paracoccidioidomycosis, histoplasmosis, blastomycosis, Klebsiella rhinoescleromatis), tumours (lymphomas, carcinoma, midline granuloma), relapsing polichondritis, sarcoidosis and Wegener disease $[2,4]$. If middle line necrosis is observed, cocaine

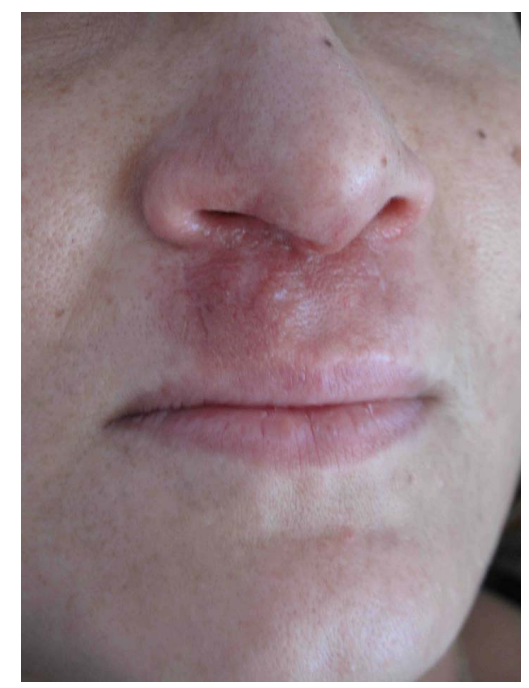

Figure 2. Aspect of the nose and nasal mucosa after two weeks of treatment. addiction must be suspected [9]. However, in a necrosis caused by cocaine use there is not granulomas neither inflammation [10].

Identification of the parasites in tissue biopsy materials obtained from skin or mucosal ulcers is the best method of diagnosis confirmation, but local parasitism must be abundant, and this is not usual in the mucosal presentation $[2,3,8]$. A diagnostic choice is parasite DNA detection by using PCR. Its sensitivity reaches around 89\% $100 \%$, but it is only available in specialized laboratories [3,8]. Mucocutaneous leishmaniasis does usually not develop a significant antibody response [11], consequently serological response in HIV patients offers less diagnostic value, because up to $40 \%$ of co-infected HIV/ Leishmania patients may present negative values in accordance with their immunological status [12]. An excellent response after treatment supports the diagnosis [13]. There are no specific treatment guidelines in mucosal leishmaniasis [2], but currently available therapy is based on pentavalent antimony and amphotericin B.

In the case of an immunodepressed patient who presents torpid evolution of mucocutaneous ulcers, it is necessary to rule out infection by Leishmania parasites. It may occur, as in our patient, that PCR and specific cultures turn out negative. A low level of parasites and the previous active therapy against the protozoa (such as Fluconazole) may lead to this. In our patient, after ruling out a cross-reaction with T. cruzi, increased value was given to Leishmania positive serology, observing that mucocutaneous forms and co-infected HIV patients usually present negative values.

\section{REFERENCES}

[1] M. M. Lessa, H. A. Lessa, T. W. Castro, A. Oliveira, A. Scherifer, et al., "Mucosal Leishmaniasis: Epidemological and Clinical Aspects,” Revista Brasileira de Otorrinolaringologia, Vol. 73, No. 6, 2007, pp. 843-847. doi:10.1590/S0034-72992007000600016

[2] E. Shwart, C. Hatz and J. Blum, "New World Cutaneous Leishmaniasis in Travellers," Lancet Infectious Diseases, Vol. 6, No. 6, 2006, pp. 342-349. doi:10.1016/S1473-3099(06)70492-3

[3] M. Mateo, I. Cruz, M. D. Flores and R. López-Vélez, "Slowly Progressing Skin Ulcers Following a Stay in Costa Rica,” Enfermedades Infecciosas y Microbiología Clínica, Vol. 23, No. 4, 2005, pp. 243-244. doi:10.1157/13073152

[4] B. Herwaldt, "Leishmaniasis," Lancet, Vol. 354, 1999, pp. 1191-1199. doi:10.1016/S0140-6736(98)10178-2

[5] J. Alvar, J. A. Ballesteros, R. Soler, A. Beniro, G. J. van Eys, et al., "Mucocutaneous Leishmaniasis due to Leishmania (Leishmania) Infantum: Biochemical Characterization,” The American Journal of Tropical Medicine and Hygiene, Vol. 43, No. 6, 1990, pp. 614-618. 
[6] P. A. van Damme, M. Keuter, S. Van Assen, P. M. De-Wilde and P. J. A. Beckers, "A Rare Case of Oral Leishmaniasis,” Lancet Infectious Diseases, Vol. 4, No. 1, 2004, p. 53. doi:10.1016/S1473-3099(03)00861-2

[7] J. M. Ramos, Z. Zubero and J. Ena, "Inmigración y VIH. Aproximación a las Enfermedades Parasitarias y Virales,"Enfermedades Infecciosas y Microbiología Clínica, Vol. 26, No. 3, 2008, pp. 42-53. doi:10.1157/13123266

[8] M. Gallego and C. Riera, "Las Leishmaniasis Humanas. Control de Calidad de la Sociedad Española de Enfermedades Infecciosas y Microbiología Clínica.” http://www.seimc.org/control/revi_Para/leish.htm. Consulted in June 6th, 2010.

[9] M. Trimarchi, G. Gregorini, F. Facchetti, M. L. Morassi, C. Manfredini, R. Maroldi, et al., "Cocaine-Induced Midline Destructive Lesions: Clinical, Radiographic, Histopathologic, and Serologic Features and Their Differentiation from Wegener Granulomatosis,” Medicine, Vol. 80,
No. 6, 2001, pp. 391-404. doi:10.1097/00005792-200111000-00005

[10] C. B. Bonner and I. Y. Castillo, "Lesión Destructiva de la Línea Media Inducida por Cocaína: Comunicación de un Caso,” Anales de Otorrinolaringología Mexicana, Vol. 54, No. 1, 2009, pp. 32-35.

[11] Centers for Disease Control \& Prevention, "National Center for Infectious Diseases, Division of Parasitic Diseases,” Consulted in 19 September 2010. http://www.dpd.cdc.gov/dpdx/HTML/Leishmaniasis.htm.

[12] J. Alvar, C. Cañavete, B. Gutiérrez-Solar, M. Jiménez, F. Laguna, et al., "Leishmania and Human Immunodeficiency Vírus Coinfection: The Firts 10 Years,” Clinical Microbiology Reviews, Vol. 10, No. 2, 1997, pp. 298-319.

[13] M. Ara, C. Mailo, G. Peon, A. Clavel, J. Cuesta, et al., "Visceral Leishmaniasis with Cutaneous Lesions in a Patient Infected with Human Immunodeficiency Virus," The British Journal of Dermatology, Vol. 139, No. 1, 1998, pp. 114-117. doi:10.1046/j.1365-2133.1998.02326.x 